\title{
Notices
}

The Midwest History of Education Society will hold its third annual meeting in late October of 1967 . Inquiries for information may be addressed to Gerald Gutek, Loyola University, Chicago.

The National Endowment for the Humanities has announced that it will accept proposals for project grants, as distinguished from fellowships, at any time.

Proposals in the areas described below may be made in any field of the humanities as defined in Public Law 89-209:

The term "humanities" includes, but is not limited to, the study of the following: language, both modern and classical; linguistics; literature; history; jurisprudence; philosophy; archaeology; the history, criticism, theory, and practice of the arts; and those aspects of the social sciences which have humanistic content and employ humanistic methods.

A. For scholarly research in the humanities, as well as for aids to research including bibliographies, indexes, and other scholarly "tools," and for fostering interchange of information in the humanities. Of particular interest are proposals for studies of the origins and development of American culture.

B. For programs to increase the educational potential of schools, colleges, and universities, and to increase the understanding and appreciation of the humanities among the public at large. Of particular interest gre proposals to strengthen the relevance of the humanities for all segments of the public.

Requests for further information or for application forms and instructions should be addressed to:

National Foundation on the Arts and the Humanities

National Endowment for the Humanities

Office of Grants

I80o G Street, N.W.

Washington, D.C. 20506 


\section{The History of an Educational Reform-}

George M. Addy's

\section{THE ENLIGHTENMENT IN THE UNIVERSITY OF SALAMANCA}

This book traces the history of intellectual and administrative reform in the University of Salamanca during the critical years from 1740 to 1808 , when the Enlightenment had its maximum impact in Spain. While deepening the understanding of this period and of Spanish culture, this work also makes a highly timely contribution to the study of any university in a chang. ing world.

$x \times i, 410 p p$.

$$
\text { LC } 66-21650
$$

\section{Duke University Press}

6697 College Station

Durham, North Carolina 27708 
